\title{
Population Pharmacokinetics and Pharmacodynamics of Linagliptin in Patients with Type 2 Diabetes Mellitus
}

\author{
Silke Retlich • Vincent Duval • Ulrike Graefe-Mody • \\ Christian Friedrich $\cdot$ Sanjay Patel • \\ Ulrich Jaehde $\cdot$ Alexander Staab
}

Published online: 31 January 2015

(C) The Author(s) 2015. This article is published with open access at Springerlink.com

\begin{abstract}
Background and Objectives Linagliptin is a dipeptidyl peptidase (DPP)-4 inhibitor, used to treat type 2 diabetes mellitus (T2DM). Population pharmacokinetic and pharmacodynamic analyses were performed to characterize the impact of clinically relevant intrinsic/extrinsic factors (covariates) on linagliptin exposure and DPP-4 inhibition in patients with T2DM.

Methods Linagliptin plasma concentrations and DPP-4 activities were obtained from four studies (two phase 1, two phase $2 b$ ). Non-linear mixed-effects modelling techniques were implemented using NONMEM software. The covariates that were studied comprised demographic information and laboratory values, including liver enzyme levels and creatinine clearance, as well as study-related factors such as metformin co-treatment. Covariate effects on parameters describing the pharmacokinetics and pharmacokinetic/ pharmacodynamic relationship were investigated using stepwise forward inclusion/backward elimination.
\end{abstract}

Electronic supplementary material The online version of this article (doi:10.1007/s40262-014-0232-4) contains supplementary material, which is available to authorized users.

S. Retlich $(\square) \cdot$ V. Duval · C. Friedrich · A. Staab

Boehringer Ingelheim Pharma GmbH \& Co. KG, Biberach,

Germany

e-mail: silke.retlich@boehringer-ingelheim.com

\section{U. Graefe-Mody}

Boehringer Ingelheim Pharma GmbH \& Co. KG, Ingelheim, Germany

S. Patel

Boehringer Ingelheim Ltd., Bracknell, Berkshire, UK

U. Jaehde

Institute of Pharmacy, Clinical Pharmacy, University of Bonn,

Bonn, Germany
Results The pharmacokinetic analysis included 6,907 measurements of plasma linagliptin concentrations from 462 patients; the pharmacokinetic/pharmacodynamic analysis included 9,674 measurements of plasma DPP-4 activity and linagliptin plasma concentrations from 607 patients. The non-linear pharmacokinetics were described by a targetmediated drug disposition model accounting for the concentration-dependent binding of linagliptin to its target, DPP-4. The difference in exposure between the 5th and 95th percentiles of the covariate distributions and median was $<20 \%$ for each single covariate. Likewise, the impact of the covariates on both the half-maximum effect $\left(\mathrm{EC}_{50}\right)$ and the concentration leading to $80 \%$ DPP-4 inhibition was $<20 \%$. Conclusion These analyses show that the investigated factors do not alter the pharmacokinetics and DPP-4 inhibitory activity of linagliptin to a clinically relevant extent and that dose adjustment is not necessary on the basis of factors including age, sex and weight.

\section{Key Points}

These analyses, reporting previously unpublished data on the pharmacokinetic and pharmacodynamic profile of linagliptin, show that factors including age, sex and weight do not alter the pharmacokinetics and dipeptidyl peptidase- 4 inhibitory activity of linagliptin to a clinically relevant extent.

These findings indicate there is no need for linagliptin dose adjustment on the basis of age, sex or weight, and they extend the findings of previous research that has shown that linagliptin does not require dose adjustment in patients with renal or hepatic impairment. 


\section{Introduction}

Linagliptin (trade name: Trajenta ${ }^{\circledR}$ ) is a dipeptidyl peptidase (DPP)-4 inhibitor, which is approved by the US Food and Drug Administration (FDA) and the European Medicines Agency (EMA) for treatment of type 2 diabetes mellitus (T2DM). Linagliptin has a unique pharmacokinetic and pharmacodynamic profile within the DPP-4 inhibitor class [1-4]. The pharmacokinetics and pharmacodynamics of linagliptin have been evaluated in healthy subjects [5-7] and in patients with T2DM [3]. Because of the high affinity and saturable binding of linagliptin to DPP-4, and the slow dissociation from the resulting enzyme-drug complex, linagliptin shows concentration-dependent protein binding in the therapeutic plasma concentration range, with the unbound fraction of linagliptin rising with increasing total linagliptin concentrations [4]. As a result, linagliptin shows non-linear pharmacokinetics after both oral and intravenous administration, with a less than dose-proportional increase in plasma concentrations in the dose range of $1-10 \mathrm{mg}[1,3$, 5]. Unlike other DPP-4 inhibitors, linagliptin is predominantly excreted unchanged in the faeces, with renal excretion being only a minor elimination route $[5,7]$. The excretion of linagliptin in the faeces is thought to result from both biliary excretion and direct P-glycoproteinmediated efflux into the gut [8]. These pharmacological characteristics allow once-daily dosing of linagliptin $5 \mathrm{mg}$, with no requirement for dose adjustment in patients with renal impairment. At present, the linagliptin clinical trials programme includes more than 4,000 patients from over 40 countries worldwide. Linagliptin $5 \mathrm{mg}$ once daily has been shown to improve glycaemic control, significantly reducing glycated haemoglobin $\left(\mathrm{HbA}_{1 \mathrm{c}}\right)$, fasting plasma glucose (FPG) and postprandial glucose (PPG) levels from baseline, compared with placebo [9-12].

To characterize the impact of clinically relevant covariates on the pharmacokinetics of linagliptin and its inhibition of plasma DPP-4 activity in patients with T2DM, two investigations were performed: (1) a population pharmacokinetic analysis; and (2) a population pharmacokinetic/pharmacodynamic analysis. The covariates weight, sex and age were of particular interest, as no dedicated phase 1 studies to investigate their effects on the pharmacokinetics/pharmacodynamics of linagliptin have been conducted.

\section{Methods}

\subsection{Study Design}

Data were obtained from four studies performed in patients with T2DM: two phase 1 studies (studies 1 and 2) and two phase $2 \mathrm{~b}$ studies (studies 3 and 4) [13, 14] (Table 1). In the phase 1 studies, a full pharmacokinetic and DPP-4 activity profile was taken on the first and last days of treatment, with trough values measured during treatment, as indicated in Table 1 . In the phase $2 \mathrm{~b}$ studies, plasma concentrations and plasma DPP-4 activity were measured at trough and at about 1 and $2 \mathrm{~h}$ after linagliptin administration at four visits (at the visit when linagliptin was first administered, then at three subsequent visits 4-5 weeks apart) and at the follow-up visit (2-3 weeks after the final linagliptin administration).

\subsection{Data Analysis}

For both population analyses, non-linear mixed-effects modelling techniques were implemented using NONMEM software (version V, level 1.1; GloboMax LLC, Hanover, MD, USA). Investigation of the covariate effects on the parameters describing the pharmacokinetics and the pharmacokinetic/pharmacodynamic relationship was undertaken using the stepwise forward inclusion/backward elimination approach. Population modelling for the pharmacokinetic and pharmacokinetic/pharmacodynamic analyses are described separately below.

\subsection{Population Pharmacokinetic Analysis}

\subsubsection{Base Model Development}

A previously developed population pharmacokinetic model for linagliptin (based on the two phase 1 studies) was used as a starting point for the current analysis [15]. In the previous analysis, linagliptin plasma concentrations were best described by a two-compartment model, including concentration-dependent protein binding in the central and peripheral compartments. This prior model was tested and was found to be suitable for describing the linagliptin plasma concentrations obtained in the two phase $2 \mathrm{~b}$ studies, which were not included in the previous analysis. The structural model used in the population pharmacokinetic analysis is shown in Fig. 1.

\subsubsection{Covariate Model Development}

The covariates that were investigated were age, weight, height, body surface area, sex, ethnic origin, smoking status, alcohol consumption status, creatinine clearance $\left(\mathrm{CL}_{\mathrm{CR}}\right)$, metformin co-medication, formulation, DPP-4 activity at baseline and levels of serum creatinine, alanine transaminase (ALT), aspartate transaminase (AST), alkaline phosphatase, gamma-glutamyl transferase (GGT), total bilirubin, urea, creatine kinase, cholesterol, C-reactive protein, triglycerides (TG) and FPG (Table 2). 
Table 1 Summary of important design characteristics of the included studies

\begin{tabular}{|c|c|c|c|c|}
\hline & \multicolumn{4}{|l|}{ Study } \\
\hline & 1 & 2 & 3 & 4 \\
\hline Phase & 1 & 1 & $2 b$ & $2 b$ \\
\hline Formulation & Powder in bottle & Tablet formulation 1 & $\begin{array}{l}\text { Tablet } \\
\text { formulation } 2\end{array}$ & $\begin{array}{l}\text { Tablet } \\
\text { formulation } 2\end{array}$ \\
\hline Linagliptin doses (mg) & $1,2.5,5,10$ & $2.5,5,10$ & $0.5,2.5,5$ & $1,5,10$ \\
\hline Duration & 12 days & 4 weeks & 12 weeks & 12 weeks \\
\hline $\begin{array}{l}\text { Number of patients on } \\
\text { linagliptin }\end{array}$ & 35 & 61 & 170 & 196 \\
\hline Add-on to metformin & No & No & No & Yes \\
\hline \multicolumn{5}{|c|}{ Sampling schemes for linagliptin plasma concentrations and plasma DPP-4 activity } \\
\hline Single-dose profile & $\begin{array}{l}\text { Day } 1 \\
\text { Before and } 0.5,1,1.5,2,3,4,6,8\end{array}$ & d $12 \mathrm{~h}$ after the first administration & \multicolumn{2}{|c|}{$\begin{array}{l}\text { Before and } 1 \text { and } 2 \mathrm{~h} \text { after the first } \\
\text { linagliptin administration }\end{array}$} \\
\hline$C_{\text {trough }}$ during treatment & $\begin{array}{l}\text { Days } 2-11 \\
\text { Before linagliptin administration }\end{array}$ & Days $2,6,12,19,26$ and 27 & \multicolumn{2}{|c|}{$\begin{array}{l}\text { At three subsequent visits } 4-5 \text { weeks } \\
\text { apart } \\
\text { Before linagliptin administration }\end{array}$} \\
\hline Overnight sample & $\begin{array}{l}\text { Day } 11 \\
18 \mathrm{~h} \text { after drug administration on } \\
\text { day } 10\end{array}$ & $\begin{array}{l}\text { Day } 28 \\
18 \mathrm{~h} \text { after drug administration on } \\
\text { day } 27\end{array}$ & \multicolumn{2}{|l|}{-} \\
\hline Steady-state profile & $\begin{array}{l}\text { Day } 12 \\
\text { Before and } 0.5,1,1.5,2,3,4,6 \text {, }\end{array}$ & $\begin{array}{l}\text { Day } 28 \\
\text { and } 12 \mathrm{~h} \text { after administration }\end{array}$ & \multicolumn{2}{|c|}{$\begin{array}{l}\text { At three visits } 4-5 \text { weeks apart } \\
1 \text { and } 2 \mathrm{~h} \text { after linagliptin } \\
\text { administration }\end{array}$} \\
\hline Samples after last dose & $\begin{array}{l}\text { Days } 13,14,16,18 \text { and } 20 \\
\text { In the morning }\end{array}$ & $\begin{array}{l}\text { Days } 29,30,33,36,39,41 \text { and } \\
\quad 43\end{array}$ & \multicolumn{2}{|c|}{$\begin{array}{l}\text { At one visit, one sample } 2-3 \text { weeks } \\
\text { after the final linagliptin } \\
\text { administration }\end{array}$} \\
\hline
\end{tabular}

$C_{\text {trough }}$ trough plasma concentration, DPP-4 dipeptidyl peptidase-4

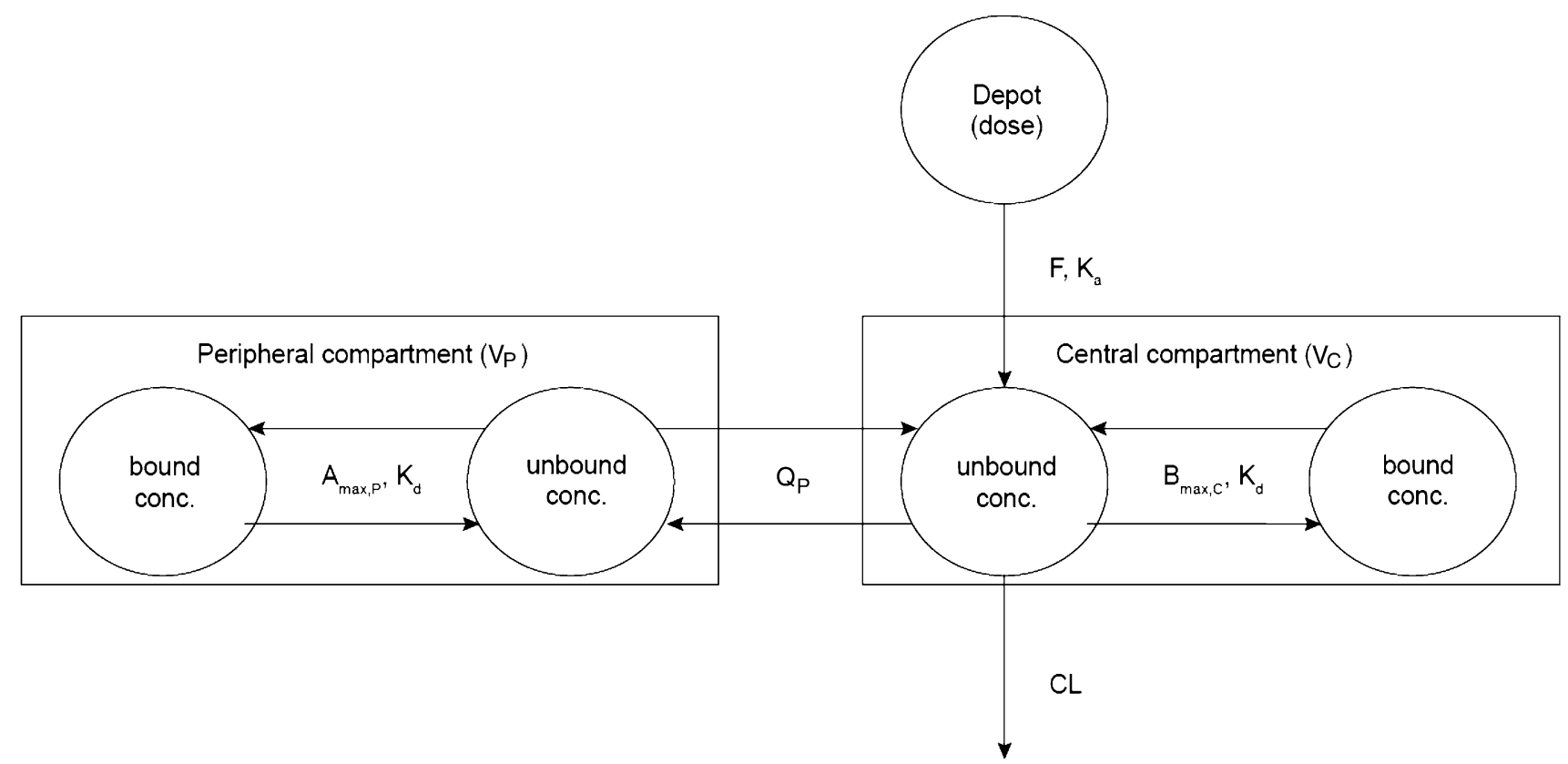

Fig. 1 Model structure of the population pharmacokinetic model. $A_{\max , P}$ number of binding sites in the peripheral compartment, $B_{\max , C}$ concentration of binding sites in the central compartment, $C L$ clearance, conc. concentration, $F$ bioavailability, $K_{a}$ absorption rate constant, $K_{d}$ affinity constant, $Q_{P}$ inter-compartmental clearance between the central and peripheral compartments, $V_{\mathrm{C}}$ central volume of distribution, $V_{P}$ peripheral volume of distribution 
Table 2 Covariates investigated by graphical and generalized additive modelling (GAM) analysis to select those to be tested in the forward inclusion/backward elimination approach performed in NONMEM

\begin{tabular}{ll}
\hline Pharmacokinetic model parameter & Covariate \\
\hline All model parameters with inter-individual variability & $\begin{array}{l}\text { Demographic information: age, weight, height, body surface area, sex, ethnic } \\
\text { origin, smoking status and alcohol consumption status } \\
\text { Dose group } \\
\\
\text { Formulation }\end{array}$ \\
$\begin{array}{l}\text { Absorption parameters with inter-individual variability } \\
\text { Listribution and elimination parameters with inter- } \\
\text { individual variability (including binding parameters) }\end{array}$ & $\begin{array}{l}\text { alanine transaminase, aspartate transaminase, alkaline phosphatase, gamma- } \\
\text { glutamyl transferase, total bilirubin, creatine kinase, cholesterol, C-reactive } \\
\text { protein, triglyceride and fasting plasma glucose }\end{array}$ \\
& Metformin treatment, baseline DPP-4 activity in relative fluorescence units
\end{tabular}

DPP-4 dipeptidyl peptidase-4

A graphical and a generalized additive modelling (GAM) analysis was carried out using SPlus software (version 7; Insightful Corporation, Seattle, WA, USA) to select the covariates to be tested in the forward inclusion/ backward elimination approach, performed in NONMEM (Fig. 2). Certain covariates were predefined on the basis of physiological considerations to be tested in the forward inclusion/backward elimination approach, independently of the results of the graphical and GAM analyses. The predefined covariates were age, sex and weight, since these were of special interest, as no dedicated phase 1 studies have yet been performed for these, as well as levels of liver enzymes (ALT and GGT) and $\mathrm{CL}_{\mathrm{CR}}$. Because of the extensive run times and high $\eta$-shrinkage (27\% bioavailability [F], $35 \%$ clearance [CL], $22 \%$ absorption rate constant $\left[K_{\mathrm{a}}\right], 24 \%$ concentration of binding sites in the central compartment $\left[B_{\max , \mathrm{C}}\right]$ and $58 \%$ central volume of distribution $\left.\left[V_{\mathrm{C}}\right]\right)$, the forward inclusion/backward elimination approach [16] was adapted: (1) a stricter inclusion criterion ( $p=0.01$ instead of $0.05, \chi^{2}, 1$ degree of freedom [df]) was applied; (2) major parts of the analysis were conducted separately per model parameter; i.e. only the typical pharmacokinetic parameter, its inter- and intra-individual variability (where applicable) and the covariate effects for the parameter of interest were estimated, all other parameters remained fixed to the base model values (for further detail on the covariate selection process, see Appendix Table 1 in the Electronic Supplementary Material). For the final step, the impact of the statistically significant covariates on the area under the plasma concentration-time curve (AUC) at steady state during one dosing interval $\left(\mathrm{AUC}_{\tau, \mathrm{ss}}\right)$ with linagliptin $5 \mathrm{mg}$ was investigated (using Berkeley Madonna software version 8.0.4; University of California, Berkeley, CA, USA) to evaluate the clinical relevance of the covariates.

\subsubsection{Model Evaluation}

Standard goodness-of-fit plots were performed to investigate the description of the plasma concentrations. Furthermore, the base model was evaluated by a visual predictive check and the final model by posterior predictive checks for the maximum and minimum plasma concentrations $\left(C_{\max }\right.$ and $\left.C_{\min }\right)$ of linagliptin. In the posterior predictive check, the inter-individual, intra-individual and residual variabilities were taken into account, but not the uncertainty in the parameter estimates.

\subsection{Population Pharmacokinetic/Pharmacodynamic Analysis}

\subsubsection{Base Model Development}

The initial plan was to simultaneously analyse linagliptin plasma concentrations and DPP-4 activity. However, this was not possible because of extensive run time ( $>5$ days) of the population pharmacokinetic model. As linagliptin plasma concentrations and plasma DPP-4 activity were measured at the same time points, and because of the direct relationship between both measurements, with no hysteresis (data not shown), it was possible to correlate linagliptin plasma concentrations directly to DPP-4 activity without use of a pharmacokinetic model. To describe the correlation between linagliptin plasma concentrations and DPP-4 activity, a simple maximum effect $\left(E_{\max }\right)$ model and a sigmoid $E_{\max }$ model were tested. Inter-individual variability was investigated for all typical parameters.

\subsubsection{Covariate Model Development}

The covariates investigated on parameters with interindividual variability were age, height, weight, body 


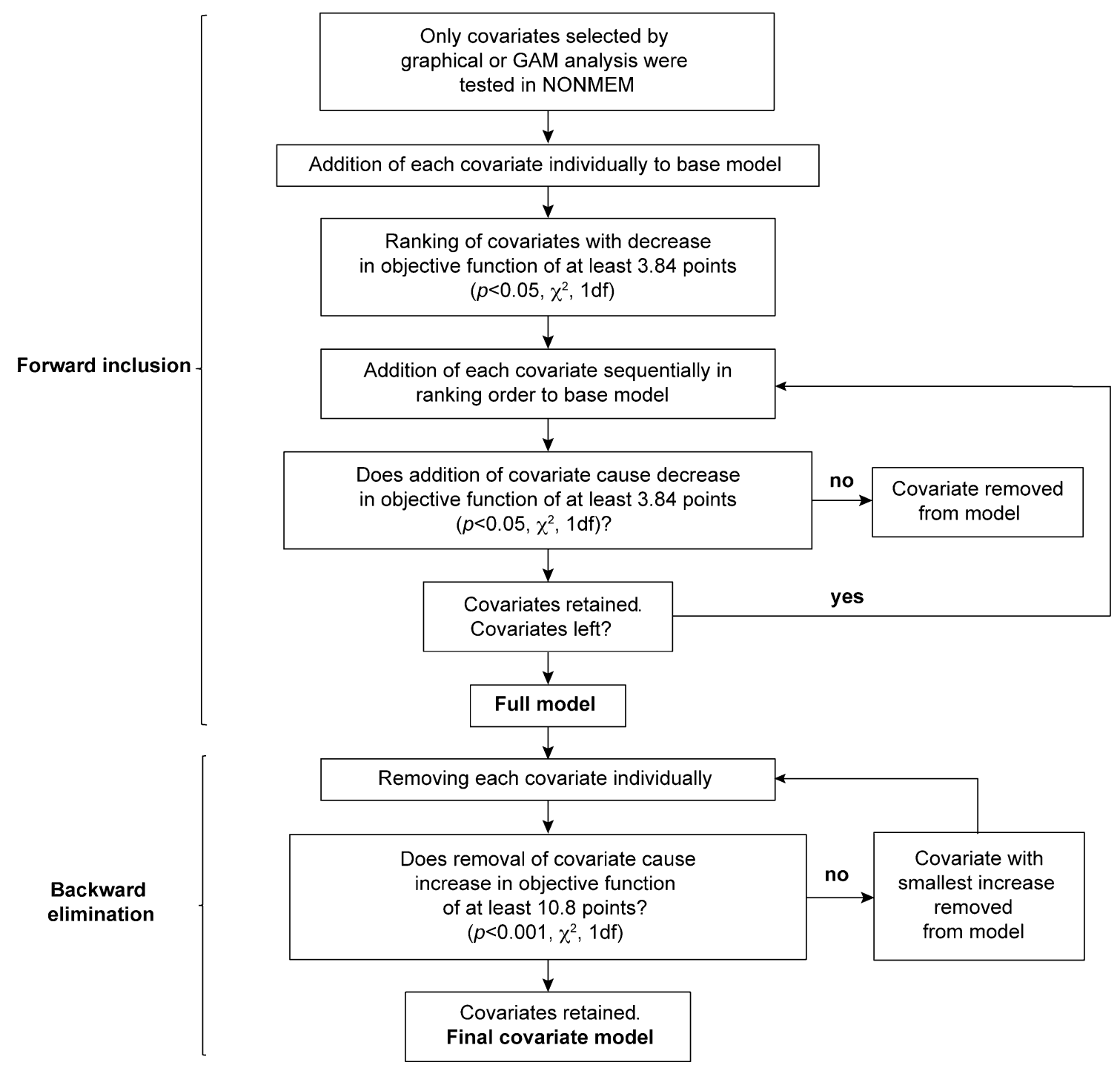

Fig. 2 Visual overview of the forward inclusion/backward elimination process. $d f$ degree of freedom, $G A M$ generalized additive modelling

surface area, sex, metformin co-medication, dose, predose DPP-4 activity, $\mathrm{CL}_{\mathrm{CR}}$ and levels of ALT, AST, TG, GGT, C-reactive protein and alkaline phosphatase. First, a graphical analysis was performed, followed by a GAM analysis. Subsequently, the covariates suggested by both procedures were tested in NONMEM, using the forward inclusion/backward elimination procedure (Fig. 2). To further evaluate the impact of the covariates, their effect on the model parameter $\mathrm{EC}_{50}$ and on the concentration leading to $80 \%$ inhibition $\left(\mathrm{EC}_{80} \%\right.$ ) of plasma DPP-4 was investigated. For continuous covariates, median and extreme covariate values (the 5th and 95th percentiles of the covariate distribution) were used; for categorical covariates, each category was evaluated. Appendix Table 2 in the Electronic Supplementary Material shows the covariates selected during the different steps of the analysis.

\subsubsection{Model Evaluation}

The final model was evaluated by a posterior predictive check, using the same approach that was used for the population pharmacokinetic model. The variables of interest were steady-state plasma DPP-4 inhibition 2 $( \pm 1) \mathrm{h}$ and $24( \pm 4) \mathrm{h}$ after linagliptin administration.

\subsubsection{Pharmacokinetic and Pharmacodynamic Effects of a Missed Dose of Linagliptin}

To determine the effect of a missed dose of linagliptin on linagliptin plasma concentrations and the degree of DPP-4 inhibition, simulations were performed using the final pharmacokinetic and pharmacokinetic/pharmacodynamic models. In the simulations, it was assumed that all patients who were included in the pharmacokinetic/ 
pharmacodynamic data set received $5 \mathrm{mg}$ linagliptin once daily. After reaching steady state, the effect of a single missed dose at a certain time was simulated.

\section{Results}

\subsection{Data Set Description}

The final data set of the pharmacokinetic analysis included 6,907 measurements of plasma linagliptin concentrations from 462 patients with T2DM. In general, the plasma concentration-time profiles in the phase $2 b$ studies showed higher variability than those in the phase 1 studies. In addition, the linagliptin plasma concentrations were apparently higher in study 4 . The final data set of the population pharmacokinetic/pharmacodynamic analysis included 9,674 measurements of plasma DPP-4 activity and corresponding linagliptin plasma concentrations from 607 patients (receiving active treatment and placebo). Baseline demographic and laboratory data from the four included studies are shown in Table 3, as well as the numbers of patients from each trial included in the data set.

\subsection{Population Pharmacokinetic Analysis}

The linagliptin plasma concentrations in all included studies were adequately described by the initial model structure, which takes into account the binding of linagliptin to its target, DPP-4. The higher variability in the phase $2 b$ studies was accounted for by different residual variability estimates dependent on the study type $(\triangle \mathrm{OBJF}$ $-2,257)$. The higher exposure in study 4 was best described by higher relative bioavailability in this study ( $\triangle \mathrm{OBJF}$ $-65)$.

In addition to higher bioavailability estimated for the add-on to metformin study 4, the covariate analysis identified the following covariates as having a statistically significant impact on linagliptin pharmacokinetics (Table 4):

- The relative bioavailability was found to decrease with increasing weight $(\triangle \mathrm{OBJF} 15)$.

- The rate of absorption was dependent on the dose ( $\triangle$ OBJF 27 ) and study/formulation ( $\triangle$ OBJF 34 ). The typical rate of absorption in study 1 (powder in the bottle formulation) was $0.9331 / \mathrm{h}$, compared with a lower rate with both tablet formulations $(0.7951 / \mathrm{h}$ [in study 2] and $0.4411 / \mathrm{h}$ [in studies 3 and 4$]$ ).

- $B_{\mathrm{max}, \mathrm{C}}$, estimated by the model, which was likely to be a reflection of the plasma DPP-4 concentration,
Table 3 Baseline demographic and laboratory information

\begin{tabular}{lll}
\hline & $\begin{array}{l}\text { Pharmacokinetics } \\
(n=462)\end{array}$ & $\begin{array}{l}\text { Pharmacokinetics/ } \\
\text { pharmacodynamics } \\
(n=607)\end{array}$ \\
\hline Number of patients in data set & \\
Study 1 & 35 & 47 \\
Study 2 & 61 & 77 \\
Study 3 & 170 & 216 \\
Study 4 & 196 & 267 \\
Male, $n(\%)$ & $302(65.4)$ & $401(66.1)$ \\
Ethnic origin, $n(\%)$ & & \\
Caucasian & $429(92.9)$ & $559(92.1)$ \\
Black & $8(1.7)$ & $15(2.5)$ \\
Asian & $7(1.5)$ & $11(1.8)$ \\
Hispanic & $18(3.9)$ & $22(3.6)$ \\
Age, years & $60(30-78)$ & $60(30-78)$ \\
Weight, kg & $89(57-132)$ & $89(55-138)$ \\
Body mass index, kg/m ${ }^{2}$ & $30.6(20.4-42.2)$ & $30.6(20.4-42.2)$ \\
Fasting plasma glucose, & $9.9(5.1-20.0)$ & $9.9(5.1-20.0)$ \\
mmol/L & & \\
Add-on to metformin & & $340(56.0)$ \\
No & $266(57.6)$ & $267(44.0)$ \\
Yes & $196(42.4)$ & \\
\hline
\end{tabular}

The data are expressed as median (range [minimum-maximum]) unless specified otherwise

correlated with the pre-dose DPP-4 activity ( $\triangle \mathrm{OBJF}$ 68 ), dose ( $\triangle$ OBJF 69$)$ and age ( $\triangle$ OBJF 14 ).

In comparison to the base model, the inter-individual variability decreased only for $K_{\mathrm{a}}(76.4$ versus $87.6 \%)$ and $B_{\text {max,C }}(15.0$ versus $29.6 \%)$ and was in the same range for bioavailability $(F), \mathrm{CL}$ and $V_{\mathrm{C}}$, indicating that only a small part of the inter-individual variability was accounted for by the investigated covariates.

Apart from some slight model misspecification around the $C_{\max }$ value, the goodness-of-fit plots showed agreement between the observed plasma concentrations and the model predictions, indicating that the model performed adequately (see Appendix Fig. 1 in the Electronic Supplementary Material), as did the visual predictive checks for the base model (see Appendix Fig. 2 in the Electronic Supplementary Material). Posterior predictive checks showed that the final model provided an adequate description of the trough plasma concentration ( $C_{\text {trough }}$ ) and $C_{\max }$ values (except for the $C_{\max }$ values of the lowest $[0.5 \mathrm{mg}]$ and highest $[10 \mathrm{mg}]$ dose groups, which were slightly outside the $90 \%$ confidence interval, although showing only a small absolute difference; for further detail, see Appendix Fig. 3 in the Electronic Supplementary Material). 
Table 4 Parameter estimates from final population pharmacokinetic model

\begin{tabular}{|c|c|c|}
\hline Parameter & Value & Description \\
\hline \multicolumn{3}{|l|}{ Typical parameter } \\
\hline$F(\%)$ & $100^{\mathrm{a}}$ & Typical relative bioavailability \\
\hline$F$ in study $4(\%)$ & 169 & Typical relative bioavailability in study 4 \\
\hline Weight_ $F^{\mathrm{b}}$ & -0.958 & Percentage change per kg change from median weight of population \\
\hline$K_{\mathrm{a}, 1}(1 / \mathrm{h})$ & 0.933 & Typical absorption rate constant study 1 (powder in bottle formulation) \\
\hline$K_{\mathrm{a}, 2}(1 / \mathrm{h})$ & 0.795 & Typical absorption rate constant study 2 (tablet formulation 1 ) \\
\hline$K_{\mathrm{a}, 3}(1 / \mathrm{h})$ & 0.441 & Typical absorption rate constant studies 3/4 (tablet formulation 2) \\
\hline Dose_ $K_{\mathrm{a}}^{\mathrm{c}}$ & -6.51 & Percentage change in $K_{\mathrm{a}}$ per dose unit change from the $5 \mathrm{mg}$ dose group \\
\hline$V_{\mathrm{C}} / F(\mathrm{~L})$ & 715 & Typical central volume of distribution \\
\hline$Q_{\mathrm{P}} / F(\mathrm{~L} / \mathrm{h})^{\mathrm{d}}$ & 412 & Typical inter-compartmental clearance between central compartment and peripheral compartment \\
\hline$V_{\mathrm{P}} / F(\mathrm{~L})^{\mathrm{d}}$ & 1,650 & Typical volume of distribution of the peripheral compartment \\
\hline $\mathrm{CL} / F(\mathrm{~L} / \mathrm{h})$ & 258 & Typical clearance of the unbound concentration \\
\hline GGT_CL $L^{\mathrm{e}, \mathrm{f}}$ & -0.0339 & Percentage change in $\mathrm{CL} / \mathrm{F}$ per U/L change from the median GGT of the population \\
\hline$B_{\max , \mathrm{C}}(\mathrm{nmol} / \mathrm{L})$ & 4.97 & Typical concentration of binding sites in the central compartment (male) \\
\hline DPP_B $B_{\max , C^{\mathrm{g}}}$ & 0.00332 & Percentage change in $B_{\max , \mathrm{C}}$ per RFU change from the median DPP-4 activity of the population \\
\hline Dose $\_B$ max, $\mathrm{C}^{\mathrm{g}}$ & 3.41 & Percentage change in $B_{\max , \mathrm{C}}$ per dose unit change from the $5 \mathrm{mg}$ dose group \\
\hline Age $\_B$ max, ${ }^{\mathrm{g}}$ & 0.561 & Percentage change in $B_{\max , \mathrm{C}}$ per year from the median age of the population \\
\hline $\mathrm{Sex} \_B_{\max , \mathrm{C}}{ }^{\mathrm{e}}$ & 0.457 & Absolute change in $B_{\max , \mathrm{C}}$ between males and females \\
\hline$K_{\mathrm{d}}(\mathrm{nmol} / \mathrm{L})^{\mathrm{d}}$ & 0.0652 & Typical affinity constant of the saturable binding \\
\hline$A_{\max , \mathrm{P}} / F(\mathrm{nmol})^{\mathrm{d}}$ & 1,650 & Typical amount of binding partner in the peripheral compartment \\
\hline \multicolumn{3}{|c|}{ Inter- and intra-individual variability } \\
\hline$\omega F(\mathrm{CV} \%)$ & 47.4 & Inter-individual variability in relative bioavailability \\
\hline Corr $F \_C L$ & -0.765 & Correlation between $\omega F$ and $\omega \mathrm{CL}$ \\
\hline$\omega \mathrm{CL}(\mathrm{CV} \%)$ & 27.5 & Inter-individual variability in clearance of the unbound concentration \\
\hline$\omega K_{\mathrm{a}}(\mathrm{CV} \%)$ & 76.4 & Inter-individual variability in the absorption rate constant \\
\hline$\omega V_{\mathrm{C}}(\mathrm{CV} \%)$ & 24.4 & Inter-individual variability in the central volume of distribution \\
\hline$\omega B_{\max , \mathrm{C}}(\mathrm{CV} \%)$ & 15.0 & Inter-individual variability in the concentration of the central binding partner \\
\hline$\pi F(\mathrm{CV} \%)$ & 40.0 & Intra-individual variability in relative bioavailability \\
\hline \multicolumn{3}{|l|}{ Residual variability } \\
\hline$\sigma_{\text {prop,phase 2a }}(\%)^{\mathrm{h}}$ & 13.6 & Residual variability studies $1 / 2$ (phase 1 ) \\
\hline$\sigma_{\text {prop,phase } 2 \mathrm{~b}}(\%)^{\mathrm{h}}$ & 38.3 & Residual variability studies 3/4 (phase 2b) \\
\hline
\end{tabular}

$C V$ coefficient of variation, $D P P-4$ dipeptidyl peptidase-4, $R F U$ relative fluorescence units

${ }^{a}$ Relative bioavailability fixed to $100 \%$

${ }^{\mathrm{b}} F_{\mathrm{i}, \mathrm{o}}=F \cdot\left(1+\right.$ weight $\_F \cdot($ weight -88$\left.)\right) \cdot \exp (\eta F+\kappa F)$

${ }^{\mathrm{c}} K_{\mathrm{a}, \mathrm{i}}=K_{\mathrm{a}}\left(1+\right.$ dose $\left.\_K_{\mathrm{a}} \cdot(\operatorname{dose}-5)\right) \cdot \exp \left(\eta K_{\mathrm{a}}\right)$

${ }^{\mathrm{d}}$ Parameters not estimated, but fixed to estimates of the previous model

e During the backward elimination process, GGT on clearance and sex on the concentration of the binding partner in the central compartment $\left(B_{\max , C}\right)$ did not reach a statistically significant level. Nevertheless, these covariates were retained in the model, as the corresponding runs did not converge adequately and, therefore, could not be accepted as final models

${ }^{\mathrm{f}} \mathrm{CL}_{\mathrm{i}}=\mathrm{CL} \cdot\left(1+\mathrm{GGT} \_\mathrm{CL} \cdot(\mathrm{GGT}-33)\right) \cdot \exp (\eta \mathrm{CL})$

${ }^{\mathrm{g}} B_{\max , \mathrm{C}, \mathrm{i}}=\left(B_{\max , \mathrm{C}}+\operatorname{sex} \_B_{\max , \mathrm{C}} \cdot \operatorname{sex}\right) \cdot\left(1+\mathrm{DPP} \_B_{\max , \mathrm{C}} \cdot(\mathrm{DPP}-12,497)\right) \cdot\left(1+\right.$ dose $\left.\_B_{\max , \mathrm{C}} \cdot(\operatorname{dose}-5)\right) \cdot\left(1+\right.$ age $\_B_{\max , \mathrm{C}}$. (age -60$)) \cdot \exp \left(\eta \cdot B_{\max , \mathrm{C}}\right)$

${ }^{\mathrm{h}}$ Coded as additive error for $\log$ transformed data

\subsection{Impact of Significant Covariates on Exposure $\left(\mathrm{AUC}_{\tau, \mathrm{ss}}\right)$}

The impact of the statistically significant covariates on the exposure to linagliptin $\left(\mathrm{AUC}_{\tau, \mathrm{ss}}\right)$ after once-daily administration of linagliptin was $<20 \%$ for each covariate (Fig. 3). The impact of weight, age and sex, the covariates of most interest, was very small compared with the overall variability in the plasma concentration-time profiles (Fig. 4). Using the 5th and 95th percentiles of the covariate 
distributions (numbers shown in parentheses), the data demonstrated that even a combination of covariate effects resulted in only a moderate impact on linagliptin exposure; i.e. the exposure changed by only $+63 \%$ or $-26 \%$, respectively, for (a) an elderly (73-year-old) female patient

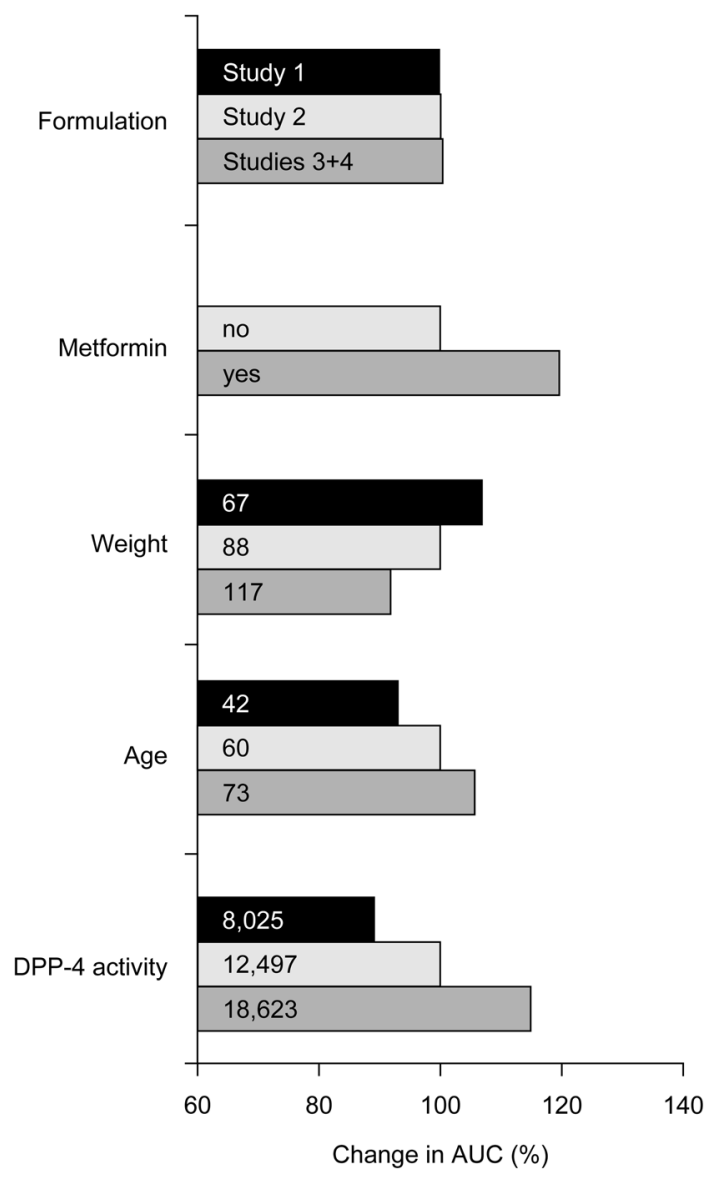

Fig. 3 Influence of statistically significant covariates (study/formulation, metformin co-medication, weight, age and baseline dipeptidyl peptidase [DPP]-4 activity) on the area under the plasma concentration-time curve (AUC) after administration of linagliptin $5 \mathrm{mg}$ of low weight $(67 \mathrm{~kg})$, with a high GGT level $(158 \mathrm{U} / \mathrm{L})$ and high pre-dose DPP-4 activity (18,623 relative fluorescence units [RFU]), on concomitant metformin therapy; or (b) a young (42-year-old), relatively heavy $(117 \mathrm{~kg})$ male patient, with a low GGT level (9.4 U/L) and low pre-dose DPP-4 activity (8,025 RFU).

\subsection{Population Pharmacokinetic/Pharmacodynamic Analysis}

DPP-4 activity correlated well with linagliptin plasma concentrations (Fig. 5). A sigmoid $E_{\max }$ model performed significantly better to describe this correlation than a simple $E_{\max }$ model ( $\triangle \mathrm{OBJF}-6,399$ ).

The individual baseline DPP-4 activities and $\mathrm{EC}_{50}$ values were correlated, an observation that is physiologically plausible: the more DPP-4 molecules that are available, the higher the baseline DPP-4 activity is and the more linagliptin molecules are needed to reduce $50 \%$ of the DPP-4 activity. Thus, the correlation between baseline DPP-4 activity and the concentration resulting in the half-maximum effect $\left(\mathrm{EC}_{50}\right)$ was implemented as follows:

$$
\begin{aligned}
\mathrm{EC}_{50, \mathrm{i}}= & \mathrm{EC}_{50} \cdot\left(1+\mathrm{BSL}_{-} \mathrm{EC}_{50} \cdot\left(\mathrm{BSL}_{\mathrm{i}}-11,600\right)\right) \\
& \cdot \exp \left(\eta \mathrm{EC}_{50}\right)
\end{aligned}
$$

The individual $\mathrm{EC}_{50}$ parameter $\left(\mathrm{EC}_{50, \mathrm{i}}\right)$ depends on the typical $\mathrm{EC}_{50}$ parameter, the typical covariate effect parameter BSL_EC E0 $_{5}$, the difference between the individual predicted baseline estimate $\left(\mathrm{BSL}_{\mathrm{i}}\right)$ and the median baseline value of 11,600 RFU, as well as the inter-individual variability of $\mathrm{EC}_{50}\left(\eta \mathrm{EC}_{50}\right)$. This implementation of the correlation was significantly superior to estimates of a correlation between $\mathrm{BSL}$ and $\mathrm{EC}_{50}$, using the block option ( $\triangle \mathrm{OBJF}-76$ ).

The final model took into account the covariate effects of GGT ( $\triangle \mathrm{OBJF} 108)$, ALT $(\triangle \mathrm{OBJF} 25)$, FPG $(\Delta \mathrm{OBJF}$ $250)$, TG ( $\triangle$ OBJF 155$)$, cholesterol ( $\triangle$ OBJF 35$)$ and sex
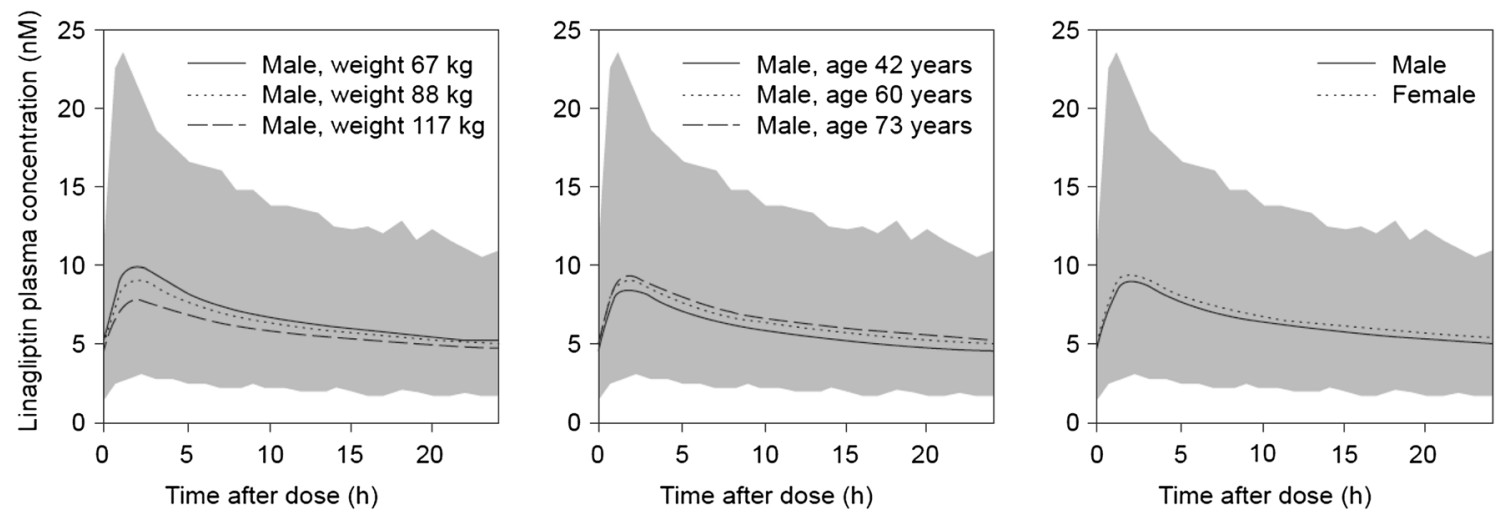

Fig. 4 Impact of weight, age and sex on linagliptin plasma concentration-time profiles after administration of linagliptin $5 \mathrm{mg}$. The overall variability was determined as the $90 \%$ prediction interval of
1,000 simulated concentration-time profiles based on the base population pharmacokinetic model (grey shaded area) 
( $\triangle$ OBJF 18 ) on the baseline DPP-4 activity, in addition to the effect of $\mathrm{TG}$ on the $\mathrm{EC}_{50}$ parameter ( $\triangle \mathrm{OBJF} 29$ ) (Table 5). Compared with the base model, inter-individual variability for $\mathrm{BSL}$ and $\mathrm{EC}_{50}$ was reduced (16.9 versus $21.6 \%$ and 15.4 versus $18.4 \%$, respectively). In addition, the residual variability of the final model was estimated to be smaller compared with the base model (14.8 versus $15.7 \%$, respectively). The goodness-of-fit plots indicated that the model provides an adequate description of the DPP-4 activity values (except for two extreme DPP-4 activity data points) (for further detail, see the Appendix and Appendix Fig. 4 in the Electronic Supplementary Material). The final model was evaluated by a posterior predictive check; the variables of interest were steady-state plasma DPP-4 inhibition at 2 and $24 \mathrm{~h}$ after linagliptin administration. The differences between the observed and predicted median DPP-4 inhibition were small (the maximum was a difference of $5 \%$ in the 24 h DPP-4 inhibition in the $2.5 \mathrm{mg}$ dose group) (see Appendix Table 3 in the Electronic Supplementary Material).

The statistically significant covariates were evaluated for their influence on the $\mathrm{EC}_{50}$ and $\mathrm{EC}_{80} \%$ (Fig. 6). With use of the 5th and 95th percentiles of the covariate distributions (numbers shown in parentheses), the data demonstrated that the combination of covariate effects led to a maximum $\mathrm{EC}_{50}$ value of $4.13 \mathrm{nM}$ and a minimum $\mathrm{EC}_{50}$ value of $2.49 \mathrm{nM}\left(\mathrm{EC}_{80} \%\right.$ maximum $7.38 \mathrm{nM}$ and minimum $4.44 \mathrm{nM}$ ), respectively, for (a) female sex and high levels of GGT (124.8 U/L), ALT (75.9 U/L), FPG (13.4 mM), TG (422.1 mg/dL) and cholesterol $(263.8 \mathrm{mg} /$ $\mathrm{dL}$ ); or (b) male sex and low levels of GGT (10.9 U/L), ALT (10.6 U/L), FPG $(5.7 \mathrm{mM})$, TG $(68.5 \mathrm{mg} / \mathrm{dL})$ and cholesterol $(98.6 \mathrm{mg} / \mathrm{dL})$.

\subsection{Pharmacokinetic and Pharmacodynamic Effects of a Missed Dose of Linagliptin}

The simulations showed that when a linagliptin dose is missed, $48 \mathrm{~h}$ after the last dose, the median linagliptin plasma concentration is $4.21 \mathrm{nM}$ ( $90 \%$ prediction interval 2.65-6.86), compared with $5.58 \mathrm{nM}(3.55-9.69) 24 \mathrm{~h}$ after dosing (Fig. 7a). The corresponding data for DPP-4 inhibition, following a missed dose, show that $48 \mathrm{~h}$ after the last linagliptin dose, enzyme inhibition remains at a median level of $69.6 \%$ (27.0-87.1), compared with $81.7 \%$ (47.5-90.5) $24 \mathrm{~h}$ after dosing. The simulations show that when a dose of linagliptin is taken after a missed dose, the linagliptin plasma concentration and the degree of DPP-4 inhibition are only slightly reduced after this dose compared with the dosing intervals before the missed dose, and the degree of DPP-4 inhibition remains above $80 \%$ (median linagliptin $C_{\text {trough }} 5.29 \mathrm{nM}$ [3.38-8.82]; median trough DPP-4 inhibition $80.3 \%$ [44.3-90.1]) (Fig. 7b).

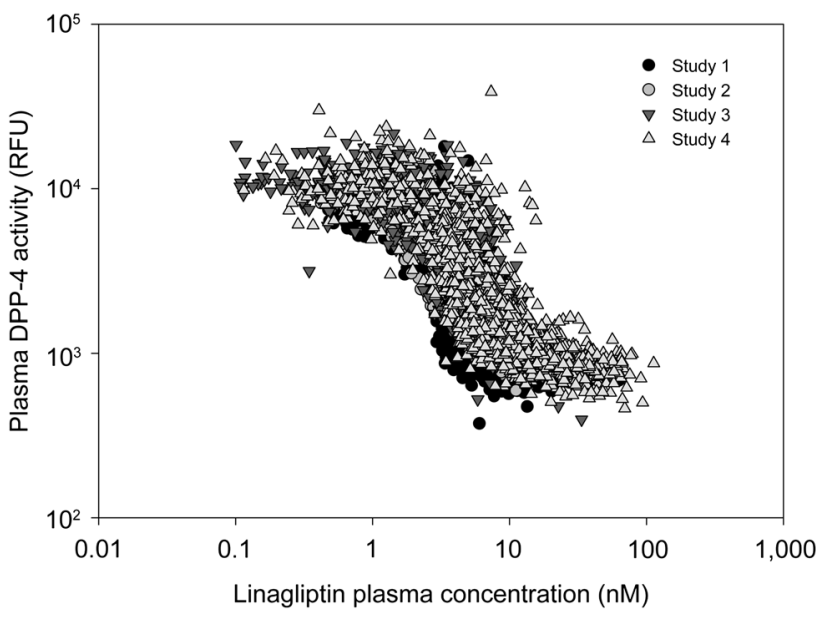

Fig. 5 Correlation of linagliptin plasma concentrations and plasma dipeptidyl peptidase (DPP)-4 activity in studies $1-4$. Placebo and predose observations are not shown because of the logarithmic scale. $R F U$ relative fluorescence units

\section{Discussion}

The current population analyses were performed to investigate the impact of clinically relevant covariates on the pharmacokinetics of linagliptin and their effects on DPP-4 inhibition. These analyses extend the findings of a previous population analysis, which showed that the non-linear pharmacokinetic profile of linagliptin is appropriately characterized by a target-mediated drug disposition model accounting for concentration-dependent binding of linagliptin to its target, DPP-4, in plasma and tissues [15]. Plasma DPP-4 activity was included in this model in a semimechanistic way by relating it to the model-calculated plasma DPP-4 occupancy with linagliptin. The description of DPP-4 inhibition by this semi-mechanistic occupancy model was comparable to a sigmoid $E_{\max }$ model, and thus the more mechanistic model was preferred. In the current analysis, however, the number of analysed data, together with the complexity of the pharmacokinetic model, led to extensively long run times of more than 5 days for the pharmacokinetic model alone. Therefore, pharmacokinetics and pharmacokinetics/pharmacodynamics were not analysed simultaneously, but two separate covariate analyses were performed, one for pharmacokinetics and one for pharmacokinetics/pharmacodynamics. For the population pharmacokinetic analysis, the target-mediated drug disposition model was used, and baseline DPP-4 activity was included as a covariate on the model parameter that reflects plasma DPP-4 concentrations $\left(B_{\max }, C\right)$ (Fig. 3) to account for the close relationship between the pharmacokinetics of linagliptin and DPP-4 activity. In the population pharmacokinetic/pharmacodynamic analysis, linagliptin plasma concentrations were directly correlated with DPP-4 activity, using a descriptive sigmoid $E_{\max }$ model. 
Table 5 Parameter estimates of the final population pharmacokinetic/pharmacodynamic model

\begin{tabular}{|c|c|c|c|}
\hline Parameter & Value & RSE $(\%)$ & Description \\
\hline \multicolumn{4}{|l|}{ Typical parameters } \\
\hline $\mathrm{BSL}_{\text {male }}(\mathrm{RFU})$ & 10,700 & 1.08 & Typical baseline DPP-4 activity for males \\
\hline $\mathrm{BSL}_{\text {female }}(\mathrm{RFU})^{\mathrm{a}}$ & 11,565 & 20.5 & Typical baseline DPP-4 activity for females \\
\hline$E_{\max }(\%)$ & 92.4 & 0.12 & Typical maximum decrease in DPP-4 activity \\
\hline $\mathrm{EC}_{50}(\mathrm{nmol} / \mathrm{L})$ & 3.06 & 1.56 & Typical linagliptin concentration that leads to half-maximum decrease in DPP-4 activity \\
\hline HILL & 3.22 & 1.82 & Typical Hill coefficient \\
\hline $\mathrm{BSL}_{-} \mathrm{EC}_{50}^{\mathrm{c}}$ & 0.00792 & 7.98 & Percentage change in $\mathrm{EC}_{50}$ per RFU change from median population baseline DPP- 4 activity \\
\hline GGT_BSL ${ }^{\mathrm{b}}$ & 0.153 & 20.4 & Percentage change in BSL per U/L change from median population baseline GGT, up to $175 \mathrm{U} / \mathrm{L}$ \\
\hline GGT_BSL2 ${ }^{\mathrm{b}}(\%)$ & 21.3 & 18.5 & Percentage change in BSL if GGT $>175 \mathrm{U} / \mathrm{L}$ \\
\hline ALT_BSL ${ }^{\mathrm{b}}$ & 0.175 & 18.5 & Percentage change in BSL per U/L change from population median baseline ALT \\
\hline FPG_BSL ${ }^{\mathrm{b}}$ & 1.46 & 12.3 & Percentage change in BSL per $\mathrm{mM}$ change from population median baseline FPG \\
\hline TRIG_BSL ${ }^{\mathrm{b}}$ & 0.0294 & 13.9 & Percentage change in BSL per $\mathrm{mg} / \mathrm{dL}$ change from population median baseline triglyceride level \\
\hline CHOL_BSL ${ }^{\mathrm{b}}$ & 0.0261 & 43.7 & Percentage change in BSL per $\mathrm{mg} / \mathrm{dL}$ change from population median baseline cholesterol level \\
\hline TRIG_EC50 ${ }^{\mathrm{c}}$ & ${ }^{-} 0.0153$ & 13.1 & Percentage change in $\mathrm{EC}_{50}$ per $\mathrm{mg} / \mathrm{dL}$ change from population median baseline triglyceride level \\
\hline
\end{tabular}

Inter-individual variability

$\begin{array}{cccl}\omega \mathrm{BSL}(\mathrm{CV} \%) & 16.9 & 7.61 & \text { Inter-individual variability in baseline DPP-4 activity } \\ \omega \mathrm{EC}_{50}(\mathrm{CV} \%) & 15.4 & 15.8 & \text { Inter-individual variability in } \mathrm{EC}_{50}\end{array}$

Residual variability

$\begin{array}{llll}\sigma_{\text {prop }}(\%) & 14.8 & 6.64 & \text { Residual variability }\end{array}$

$A L T$ alanine transaminase, $C V$ coefficient of variation, $D P P-4$ dipeptidyl peptidase-4, FPG fasting plasma glucose, GGT gamma-glutamyl transferase, $R F U$ relative fluorescence units, $R S E$ relative standard error

${ }^{\text {a }}$ Estimated as $\mathrm{BSL}_{\text {male }}+865 \mathrm{RFU}$

${ }^{\mathrm{b}} \mathrm{BSL}_{\mathrm{i}}=\mathrm{BSL} \cdot\left(1+\mathrm{GGT} \_\mathrm{BSL} \cdot(\mathrm{GGT}-32.3)\right) \cdot\left(1+\mathrm{ALT} \_\mathrm{BSL} \cdot(\mathrm{ALT}-28.8)\right) \cdot(1+$ FPG_BSL$\cdot(\mathrm{FPG}-8.90)) \cdot(1+\mathrm{TRIG} B \mathrm{BSL} \cdot(\mathrm{TRIG}-160))$. $(1+\mathrm{CHOL} \cdot(\mathrm{CHOL}-183)) \cdot \exp (\eta \mathrm{BSL}) \quad$ if $\quad$ GGT $>175: \quad$ BSL $_{\mathrm{i}}=\mathrm{BSL} \cdot\left(1+\mathrm{GGT} \_\right.$BSL2 $\left.)\right) \cdot(1+$ ALT_BSL $\cdot($ ALT -28.8$)) \cdot(1+$ FPG_BSL $($ FPG -8.90$)) \cdot(1+$ TRIG_BSL·(TRIG -160$)) \cdot(1+$ CHOL $\cdot(C H O L-183)) \cdot \exp (\eta$ BSL $)$

${ }^{\mathrm{c}} \mathrm{EC}_{50, \mathrm{i}}=\mathrm{EC}_{50} \cdot\left(1+\mathrm{BSL}_{-} \mathrm{EC}_{50} \cdot\left(\mathrm{BSL}_{\mathrm{i}}-11,600\right)\right) \cdot\left(1+\mathrm{TRIG}_{-} \mathrm{EC}_{50} \cdot(\mathrm{TRIG}-160)\right) \cdot \exp \left(\eta \mathrm{EC}_{50}\right)$

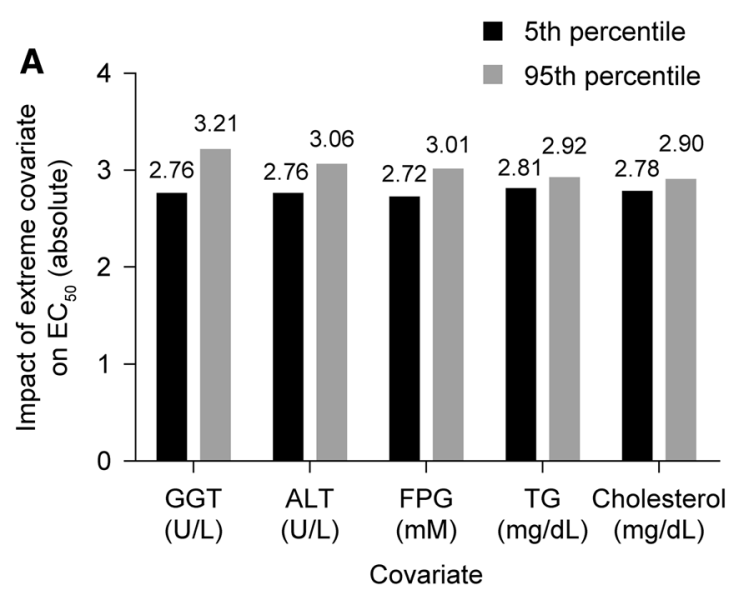

Fig. 6 Impact of statistically significant covariates on a half-maximum effect $\left(\mathrm{EC}_{50}\right)$ values and $\mathbf{b}$ concentration leading to $80 \%$ inhibition $\left(\mathrm{EC}_{80} \%\right)$ values. 5th and 95th percentiles of laboratory values: gamma-glutamyl transferase (GGT) 10.9 and $124.8 \mathrm{U} / \mathrm{L}$;

\subsection{Population Pharmacokinetic Study}

The previously developed target-mediated drug disposition model was found to also adequately describe the linagliptin

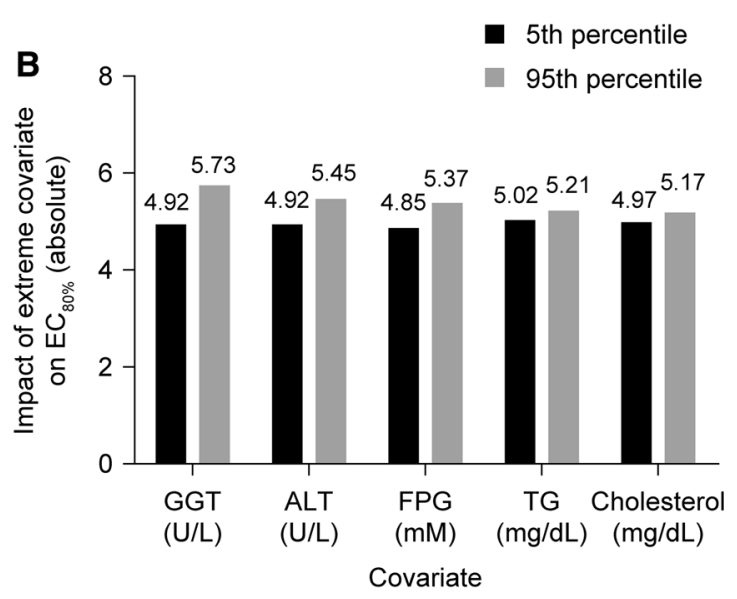

alanine transaminase (ALT) 10.6 and $75.9 \mathrm{U} / \mathrm{L}$; fasting plasma glucose (FPG) 5.7 and $13.4 \mathrm{mM}$; triglycerides (TG) 68.5 and $422.1 \mathrm{mg} / \mathrm{dL}$; cholesterol 98.6 and $263.8 \mathrm{mg} / \mathrm{dL}$

plasma concentrations obtained in the two phase $2 \mathrm{~b}$ studies, which were not included in the previous analysis. Some minor model misspecifications occurred during absorption. This may have been due to the fact that a first-order process 


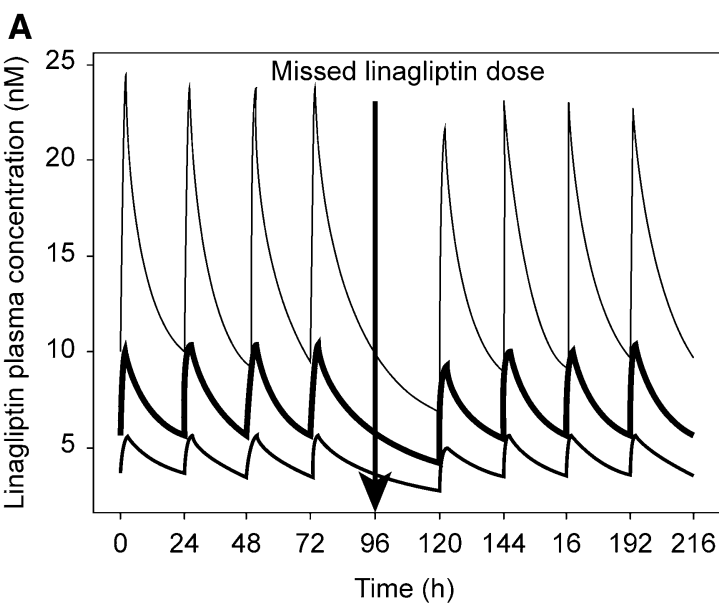

Fig. 7 a Steady-state pharmacokinetic-time profile after administration of linagliptin $5 \mathrm{mg}$. The plot shows four regular linagliptin dosings (time $0-72 \mathrm{~h}$ ), followed by a missed dose at $96 \mathrm{~h}$ and four regular dosings at times between 120 and $216 \mathrm{~h}$. b Steady-state pharmacodynamic-time profile after administration of four doses of

had not completely characterized the absorption of linagliptin, or it may have been a result of a factor that was not investigated during the covariate analysis. For most patients, only two measurements in the absorption phase per visit were available; thus, the pharmacokinetic model is more suitable for characterization of the overall exposure to linagliptin rather than its absorption.

The impact of the investigated covariates, including age, weight and sex, on the overall linagliptin exposure (AUC) was considered to be minor (all $<20 \%$ ). These effects are well within the commonly used acceptance criteria for bioequivalence [17] and are therefore not considered to be clinically relevant.

The covariate analysis showed only a minor effect of age: for example, linagliptin exposure was increased by only $13.8 \%$ in a 73-year-old patient compared with exposure in a 42-year-old patient (73 and 42 years were the 95th and 5th percentile of the age distribution in the current analysis). The minor impact of age on exposure to linagliptin is consistent with the known pharmacokinetic properties of linagliptin. Although age-dependent changes in distribution, metabolism and renal elimination have been reported for many drugs, these changes are not expected to have a clinically important effect on linagliptin, which is only slightly lipophilic; therefore, age-related changes in body composition are not likely to affect its pharmacokinetic characteristics $[5,7]$. Weight showed only a small impact on linagliptin exposure $(5.9 \%$ increase and $8.7 \%$ decrease at the 5th and 95th percentiles, respectively) and was found to be a covariate on the relative bioavailability of linagliptin (bioavailability decreased linearly by $0.96 \%$ for every $1 \mathrm{~kg}$ increase in weight). However, because the data that were used were gathered following oral

\section{B}

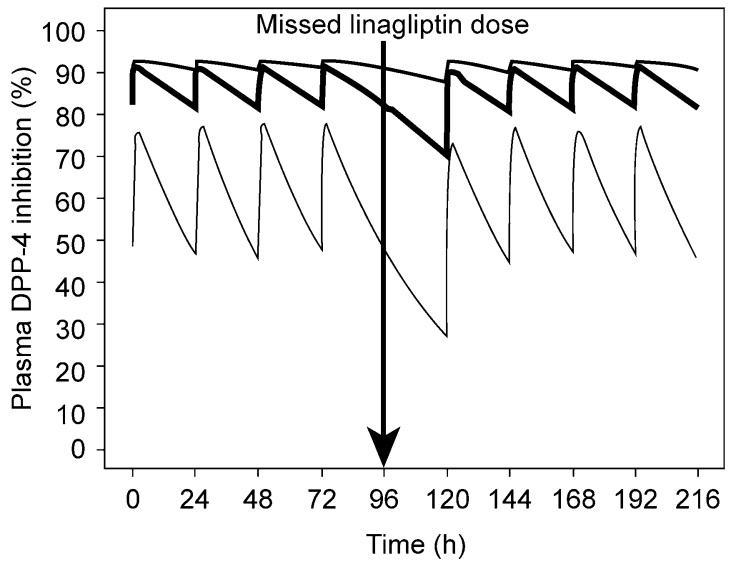

linagliptin $5 \mathrm{mg}$ (time $0-72 \mathrm{~h}$ ), followed by a missed dose at $96 \mathrm{~h}$ and regular dosing at times between 120 and $216 \mathrm{~h}$. The median profile is shown as the bold line, with the lighter lines either side indicating the $90 \%$ prediction interval. DPP-4 dipeptidyl peptidase-4

administration of linagliptin, this finding may have been due to differences in apparent clearance and/or volumes of distribution among obese individuals. A small sex-related difference in the pharmacokinetic profile of linagliptin was initially observed, which was no longer statistically significant in co-estimation of all covariate effects in the backward elimination.

In the add-on to metformin study (study 4), the exposure was around $20 \%$ higher than that observed in the studies of linagliptin monotherapy (studies 1-3). A previous study of the drug-drug interaction of linagliptin and metformin showed a similar increase in linagliptin exposure when it was administered with metformin, with no significant change in the $C_{\max }$ or terminal half-life of linagliptin; therefore, these changes were not considered to be relevant [18]. Other covariates that underwent exploratory investigation, such as $\mathrm{CL}_{\mathrm{CR}}$ and liver enzyme levels, showed no effect, or only a minor impact, on linagliptin exposure. These findings suggest that neither liver nor kidney impairment alter the pharmacokinetic profile of linagliptin; however, only patients with normal liver function and normal renal function or mild renal impairment were included, so conclusions about the effects of renal or liver impairment on the pharmacokinetic profile of linagliptin cannot be made from the current analyses. Meanwhile, dedicated studies have shown that neither renal impairment nor liver impairment affect the pharmacokinetic characteristics of linagliptin $[19,20]$.

Even when all covariates that statistically influenced the evaluated pharmacokinetic parameters were combined, in a worst-case scenario, this was not considered to have a clinically relevant effect on the safety and efficacy of linagliptin. With regard to the largest decrease in exposure 
( $-26 \%$ ) for the $5 \mathrm{mg}$ dose, this would still be regarded as effective therapy, as the linagliptin exposure is within the range of the $2.5 \mathrm{mg}$ dose group. The largest increase in exposure $(+63 \%)$ for the $5 \mathrm{mg}$ dose can still be regarded as having acceptable safety on the basis of the currently available safety data, including a single rising-dose study of healthy volunteers, where a single dose of linagliptin was shown to be well tolerated up to a dose of $600 \mathrm{mg}$ [5]. These findings indicate that the evaluated covariates do not affect the pharmacokinetic characteristics of linagliptin in a clinically important manner and that no dose adjustment is needed on the basis of age, sex or weight.

As a result of extensive run times and high $\eta$-shrinkage, the covariate selection process [16] was adapted (see the 'Covariate Model Development' section for details). In order to ensure that no covariate with a major impact on pharmacokinetics was missed, several covariates were predefined on the basis of physiological considerations to be tested in the forward inclusion/backward elimination approach; these included age, sex and weight, as well as levels of liver enzymes (ALT and GGT) and $\mathrm{CL}_{\mathrm{CR}}$. Moreover, graphical analysis of the correlation between the measured linagliptin concentrations and the investigated covariates for patients receiving linagliptin $5 \mathrm{mg}$ (data not shown) confirmed the results of the model-based covariate analysis, demonstrating that none of the tested covariates had a major impact on the $C_{\text {trough }}$ or $C_{\max }$ values.

\subsection{Population Pharmacokinetic/Pharmacodynamic Study}

The relationship between linagliptin plasma concentrations and plasma DPP-4 activity was best described by a sigmoid $E_{\max }$ model with typical $\mathrm{EC}_{50}$ values of $2.84 \mathrm{nM}$ for males and $3.05 \mathrm{nM}$ for females, and a typical Hill coefficient of 3.22. A correlation between $\mathrm{EC}_{50}$ and baseline DPP-4 activity was accounted for in the model. Thus, covariates affecting baseline DPP-4 activity also affect the $\mathrm{EC}_{50}$ value. The rationale for this is based on the premise that a higher DPP-4 plasma concentration, represented by higher DPP-4 baseline activity, necessitates a higher linagliptin concentration for half-maximum DPP-4 inhibition to be reached.

Individually, the investigated covariates, including age, sex and weight, had only a small impact on the baseline DPP-4 activity, the $\mathrm{EC}_{50}$ and the $\mathrm{EC}_{80} \%$. Age had no impact on DPP-4 activity, an observation that is consistent with previous findings [21], although some studies have shown a correlation $[22,23]$, suggesting that the impact of age on DPP-4 activity, if it exists, is minor. Neither weight nor body mass index were shown to affect DPP-4 activity, which is in accordance with the findings of previous research $[22,24]$. Baseline DPP-4 activity, and thus the
$\mathrm{EC}_{50}$, was slightly higher in females than in males in the present analysis (11,565 versus $10,700 \mathrm{RFU})$. In contrast, previous studies have suggested slightly lower DPP-4 activity in females than in males [24], or no influence of sex on DPP-4 activity [21]. Baseline DPP-4 activity was correlated with the levels of the liver enzymes GGT, ALT and AST, a finding that is consistent with previous observations [24]. Baseline DPP-4 activity was also correlated with FPG levels, a finding that is consistent with the knowledge that DPP-4 inhibition is linked to glucoselowering efficacy [25] and is correlated with $\mathrm{HbA}_{1 \mathrm{c}}$ and FPG levels in patients with T2DM [22, 23].

Even the combined influence of all significant covariates, in a worst-case scenario, only changed the $\mathrm{EC}_{50}$ from a minimum of $2.49 \mathrm{nM}$ to a maximum of $4.13 \mathrm{nM}$, and changed the $\mathrm{EC}_{80} \%$ from a minimum of $4.44 \mathrm{nM}$ to a maximum of $7.38 \mathrm{nM}$. In view of this finding, and the high variability in the DPP-4 inhibition/ $\mathrm{HbA}_{1 \mathrm{c}}$ relationship, the investigated covariates, including weight, sex and age, are not considered to be clinically important. Moreover, a scenario leading to higher baseline DPP-4 activity, and thus higher $\mathrm{EC}_{50}$ or $\mathrm{EC}_{80} \%$ values, would lead to an increase in linagliptin concentrations, since baseline DPP-4 activity was shown to be one of the main factors influencing linagliptin exposure.

The populations that were evaluated contained mostly Caucasian patients, with insufficient numbers of patients of black or Asian ethnicity to be included in the analyses. However, recent studies of linagliptin in Asian (Japanese) [26] and black subjects [27] reported that it exhibited pharmacokinetic/pharmacodynamic profiles similar to those observed in Caucasian subjects.

\subsection{Simulation}

The simulations of steady-state pharmacokinetic and pharmacodynamic-time profiles after administration of linagliptin showed that $24 \mathrm{~h}$ after a dose of linagliptin is missed, the median DPP-4 inhibition remains at about $70 \%$, suggesting that most patients will continue to experience glucose-lowering efficacy after a missed dose of linagliptin $5 \mathrm{mg}$. This pharmacological attribute may translate into clinical benefits for patients with poor adherence who might sometimes miss a dose, suggesting that this would have a minimal impact on the long-term efficacy of therapy. However, this has not been confirmed in longer-term prospective clinical studies in patients with T2DM.

\section{Conclusion}

The findings of these analyses, reporting previously unpublished data on the pharmacokinetic and 
pharmacodynamic profile of linagliptin, show that factors including age, sex and weight do not significantly alter the pharmacokinetics and DPP-4 inhibitory activity of linagliptin. These findings are consistent with clinical data on the analysed covariates, which have shown that factors such as weight, sex, race and age do not significantly alter the efficacy and safety of linagliptin [28-31]. These results also indicate that there is no need for linagliptin dose adjustment on the basis of age, sex or weight, and they extend the findings of previous research showing that linagliptin does not require dose adjustment in patients with renal or hepatic impairment [19, 20].

Acknowledgments The main results of this population analysis have been published previously [28]. The authors were fully responsible for all content and editorial decisions, were involved in all stages of manuscript development and approved the final version. Medical writing assistance, supported financially by Boehringer Ingelheim, was provided by Jennifer Edwards MB BS of Envision Scientific Solutions during the preparation of this manuscript.

Conflicts of interest At the time of the analysis performed in this study, S. R. was a Ph.D. student at the University of Bonn and received a grant from Boehringer Ingelheim; she is now an employee of Boehringer Ingelheim. U. G. M., S. P. and A. S. are all employees of Boehringer Ingelheim. V. D. was an employee of Boehringer Ingelheim at the time of the analysis; he is now an employee of Novartis. C. F. was an employee of Boehringer Ingelheim while the study took place; he is now an employee of Bayer Healthcare. U. J. has received research Grants from Boehringer Ingelheim (between 2006 and 2011) and received a research Grant from Boehringer Ingelheim for the present study.

Open Access This article is distributed under the terms of the Creative Commons Attribution Noncommercial License which permits any noncommercial use, distribution, and reproduction in any medium, provided the original author(s) and the source are credited.

\section{References}

1. Deacon CF, Holst JJ. Linagliptin, a xanthine-based dipeptidyl peptidase-4 inhibitor with an unusual profile for the treatment of type 2 diabetes. Expert Opin Investig Drugs. 2010;19(1):133-40.

2. Fuchs H, Binder R, Greischel A. Tissue distribution of the novel DPP-4 inhibitor BI 1356 is dominated by saturable binding to its target in rats. Biopharm Drug Dispos. 2009;30(5):229-40.

3. Heise T, Graefe-Mody EU, Hüttner S, Ring A, Trommeshauser D, Dugi KA. Pharmacokinetics, pharmacodynamics and tolerability of multiple oral doses of linagliptin, a dipeptidyl peptidase4 inhibitor in male type 2 diabetes patients. Diabetes Obes Metab. 2009;11(8):786-94.

4. Thomas L, Eckhardt M, Langkopf E, Tadayyon M, Himmelsbach F, Mark M. (R)-8-(3-Amino-piperidin-1-yl)-7-but-2-ynyl-3methyl-1-(4-methyl-quinazoli n-2-ylmethyl)-3,7-dihydro-purine2,6-dione (BI 1356), a novel xanthine-based dipeptidyl peptidase 4 inhibitor, has a superior potency and longer duration of action compared with other dipeptidyl peptidase-4 inhibitors. J Pharmacol Exp Ther. 2008;325(1):175-82.

5. Hüttner S, Graefe-Mody EU, Withopf B, Ring A, Dugi KA. Safety, tolerability, pharmacokinetics, and pharmacodynamics of single oral doses of BI 1356, an inhibitor of dipeptidyl peptidase 4, in healthy male volunteers. J Clin Pharmacol. 2008;48(10): 1171-8.

6. Retlich S, Duval V, Ring A, Staab A, Huttner S, Jungnik A, et al. Pharmacokinetics and pharmacodynamics of single rising intravenous doses $(0.5 \mathrm{mg}-10 \mathrm{mg})$ and determination of absolute bioavailability of the dipeptidyl peptidase- 4 inhibitor linagliptin (BI 1356) in healthy male subjects. Clin Pharmacokinet. 2010;49(12):829-40.

7. Blech S, Ludwig-Schwellinger E, Gräfe-Mody EU, Withopf B, Wagner K. The metabolism and disposition of the oral dipeptidyl peptidase-4 inhibitor, linagliptin, in humans. Drug Metab Dispos. 2010;38(4):667-78.

8. Fuchs H, Runge F, Held HD. Excretion of the dipeptidyl peptidase-4 inhibitor linagliptin in rats is primarily by biliary excretion and P-gp-mediated efflux. Eur J Pharm Sci. 2012;45(5):533-8.

9. Del Prato S, Barnett AH, Huisman H, Neubacher D, Woerle HJ, Dugi KA. Effect of linagliptin monotherapy on glycaemic control and markers of beta-cell function in patients with inadequately controlled type 2 diabetes: a randomized controlled trial. Diabetes Obes Metab. 2011;13(3):258-67.

10. Owens DR, Swallow R, Dugi KA, Woerle HJ. Efficacy and safety of linagliptin in persons with type 2 diabetes inadequately controlled by a combination of metformin and sulphonylurea: a 24-week randomized study. Diabet Med. 2011;28(11):1352-61.

11. Taskinen MR, Rosenstock J, Tamminen I, Kubiak R, Patel S, Dugi KA, et al. Safety and efficacy of linagliptin as add-on therapy to metformin in patients with type 2 diabetes: a randomized, double-blind, placebo-controlled study. Diabetes Obes Metab. 2011;13(1):65-74.

12. Forst T, Uhlig-Laske B, Ring A, Ritzhaupt A, Graefe-Mody U, Dugi KA. The oral DPP-4 inhibitor linagliptin significantly lowers $\mathrm{HbA}_{1 \mathrm{c}}$ after 4 weeks of treatment in patients with type 2 diabetes mellitus. Diabetes Obes Metab. 2011;13(6):542-50.

13. Singh-Franco D, McLaughlin-Middlekauff J, Elrod S, Harrington C. The effect of linagliptin on glycaemic control and tolerability in patients with type 2 diabetes mellitus: a systematic review and meta-analysis. Diabetes Obes Metab. 2012;14(8):694-708.

14. Forst T, Uhlig-Laske B, Ring A, Graefe-Mody U, Friedrich C, Herbach K, et al. Linagliptin (BI 1356), a potent and selective DPP-4 inhibitor, is safe and efficacious in combination with metformin in patients with inadequately controlled type 2 diabetes. Diabet Med. 2010;27(12):1409-19.

15. Retlich S, Duval V, Graefe-Mody U, Jaehde U, Staab A. Impact of target-mediated drug disposition on linagliptin pharmacokinetics and DPP-4 inhibition in type 2 diabetic patients. J Clin Pharmacol. 2010;50(8):873-85.

16. Savic RM, Karlsson MO. Evaluation of an extended grid method for estimation using nonparametric distributions. AAPS J. 2009;11(3):615-27.

17. US Department of Health and Human Services, Food and Drug Administration, Center for Drug Evaluation and Research (CDER). Guidance for industry: bioavailability and bioequivalence studies for orally administered drug products-general considerations. 2003. http://www.fda.gov/downloads/Drugs/.../ Guidances/ucm070124.pdf. Accessed 10 Sep 2013.

18. Graefe-Mody EU, Padula S, Ring A, Withopf B, Dugi KA. Evaluation of the potential for steady-state pharmacokinetic and pharmacodynamic interactions between the DPP-4 inhibitor linagliptin and metformin in healthy subjects. Curr Med Res Opin. 2009;25(8):1963-72.

19. Graefe-Mody U, Rose P, Retlich S, Ring A, Waldhauser L, Cinca $\mathrm{R}$, et al. Pharmacokinetics of linagliptin in subjects with hepatic impairment. Br J Clin Pharmacol. 2012;74(1):75-85.

20. Graefe-Mody U, Friedrich C, Port A, Ring A, Retlich S, Heise T, et al. Effect of renal impairment on the pharmacokinetics of the 
dipeptidyl peptidase-4 inhibitor linagliptin. Diabetes Obes Metab. 2011;13(10):939-46.

21. Cordero OJ, Ayude D, Nogueira M, Rodriguez-Berrocal FJ, de la Cadena MP. Preoperative serum CD26 levels: diagnostic efficiency and predictive value for colorectal cancer. Br J Cancer. 2000;83(9):1139-46.

22. Mannucci E, Pala L, Ciani S, Bardini G, Pezzatini A, Sposato I, et al. Hyperglycaemia increases dipeptidyl peptidase IV activity in diabetes mellitus. Diabetologia. 2005;48(6):1168-72.

23. Ryskjaer J, Deacon CF, Carr RD, Krarup T, Madsbad S, Holst J, et al. Plasma dipeptidyl peptidase-IV activity in patients with type- 2 diabetes mellitus correlates positively with $\mathrm{HbA}_{1 \mathrm{c}}$ levels, but is not acutely affected by food intake. Eur $\mathbf{J}$ Endocrinol. 2006;155(3):485-93.

24. Durinx C, Neels H, Van der Auwera JC, Naelaerts K, Scharpe S, De Meester I. Reference values for plasma dipeptidyl-peptidase IV activity and their association with other laboratory parameters. Clin Chem Lab Med. 2001;39(2):155-9.

25. Drucker DJ. Dipeptidyl peptidase-4 inhibition and the treatment of type 2 diabetes: preclinical biology and mechanisms of action. Diabetes Care. 2007;30(6):1335-43.

26. Horie Y, Kanada S, Watada H, Sarashina A, Taniguchi A, Hayashi $\mathrm{N}$, et al. Pharmacokinetic, pharmacodynamic, and tolerability profiles of the dipeptidyl peptidase-4 inhibitor linagliptin: a 4-week multicenter, randomized, double-blind, placebo-controlled phase
IIa study in Japanese type 2 diabetes patients. Clin Ther. 2011;33(7):973-89.

27. Friedrich C, Glund S, Lionetti D, Kissling CJ, Righetti J, Patel S, et al. Pharmacokinetic and pharmacodynamic evaluation of linagliptin in African American patients with type 2 diabetes mellitus. Br J Clin Pharmacol. 2013;76(3):445-54.

28. Graefe-Mody U, Retlich S, Friedrich C. Clinical pharmacokinetics and pharmacodynamics of linagliptin. Clin Pharmacokinet. 2012;51(7):411-27.

29. Barnett AH, Huisman H, Jones R, von Eynatten M, Patel S, Woerle HJ. Linagliptin for patients aged 70 years or older with type 2 diabetes inadequately controlled with common antidiabetes treatments: a randomised, double-blind, placebo-controlled trial. Lancet. 2013;382(9902):1413-23.

30. Inagaki N, Watada H, Murai M, Kagimura T, Gong Y, Patel S, et al. Linagliptin provides effective, well-tolerated add-on therapy to pre-existing oral antidiabetic therapy over 1 year in Japanese patients with type 2 diabetes. Diabetes Obes Metab. 2013;15(9):833-43.

31. Thrasher J, Ahmed A, Daniels K, Patel S, Whetteckey J. Randomized, placebo-controlled, double-blind, 24-week study of linagliptin $5 \mathrm{mg} /$ day in black/African American patients with type 2 diabetes. AACE 21st Annual Meeting and Clinical Congress; 23-27 May 2012; Philadelphia, PA. Abstract 206. 